Rapid Reviews COVID-19•

\title{
Reviews of "SARS-CoV-2 spike downregulates tetherin to enhance viral spread"
}

Chin-Tien Wang, Barry Milavetz ${ }^{1}$

${ }^{1}$ University of North Dakota, Biomedical Sciences Grand Forks, North Dakota 58202 UNITED STATES

Published on: Aug 13, 2021

License: Creative Commons Attribution 4.0 International License (CC-BY 4.0). 
To read the original manuscript, click the link above.

Summary of Reviews: This preprint demonstrates that host cells employ a known pathway in which interferon-induced tetherin "tethers" SARS-CoV-2 to the inner plasma membrane to restrict viral exit. Reviewers recognize the data as reliable with minor revisions needed.

\section{Reviewer 1 (Chin-Tien Wang) | $|\mathrm{|c|}| \mathrm{\square}$}

Reviewer 2 (Barry Milavetz) | प्र०ण

$$
\begin{aligned}
& \text { RR:C19 Strength of Evidence Scale Key. }
\end{aligned}
$$

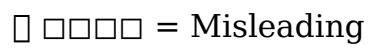

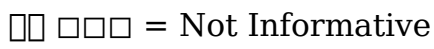

$$
\begin{aligned}
& \text { प्रा पि = Potentially Informative }
\end{aligned}
$$

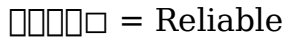

$$
\begin{aligned}
& \text { प्राप्र = Strong }
\end{aligned}
$$

To read the reviews, click the links below. 